\title{
Effect of mineral filler type on autogenous shrinkage of self-compacting concrete
}

\author{
B. Craeye ${ }^{\text {a }}$, G. De Schutter ${ }^{\text {a,* }}$, B. Desmet ${ }^{\text {b }}$, J. Vantomme ${ }^{\text {b }}$ G. Heirman ${ }^{\text {c }}$ L. Vandewalle ${ }^{\text {c }}$, Ö. Cizer ${ }^{\text {c }}$, \\ S. Aggoun ${ }^{\mathrm{d}}$, E.H. Kadri ${ }^{\mathrm{d}}$ \\ a Magnel Laboratory for Concrete Research, Department of Structural Engineering, Ghent University, B9052 Ghent, Belgium \\ b Department of Civil and Materials Engineering, Royal Military Academy, Brussels, Belgium \\ ${ }^{c}$ Department of Civil engineering, K.U.Leuven, Belgium \\ d Laboratory L2MGC, University of Cergy Pontoise, F9500 Cergy Pontoise, France
}

\section{A R T I C L E I N F O}

Article history:

Received 22 September 2009

Accepted 22 January 2010

\section{Keywords}

Self-compacting concrete

Filler [D]

Shrinkage [C]

\begin{abstract}
A B S T R A C T
Based on an experimental programme, including autogenous shrinkage tests on concrete, ultrasonic monitoring of fresh concrete, and mercury intrusion porosimetry, the influence of the filler type on the autogenous shrinkage of self-compacting concrete has been investigated. The onset of percolating structure formation (time zero) is influenced by the filler type due to a possible accelerating effect of the filler on the cement hydration. Limestone filler accelerates the hydration process, and reduces time zero, while this is not the case when using quartzite filler. Using fly ash, showing only a slight acceleration, a slight reduction of time zero is obtained. A very significant swelling peak is noticed during the first day. This swelling peak is not a measuring artefact, but is caused mainly by water absorption on the filler surface and resulting disjoining pressure. Some part of the swelling peak might also be caused by $\mathrm{Ca}(\mathrm{OH})_{2}$ crystallisation. The fineness of the filler is an important factor for this swelling behaviour, although also the nature of the filler seems to have an influence. The superplasticiser also interacts with the fillers, influencing the swelling behaviour. The different filler types used in this study did not lead to significant differences in critical pore diameter of the microstructure. This might explain why no significant differences have been found in final autogenous shrinkage values using the different filler types.
\end{abstract}

(c) 2010 Elsevier Ltd. All rights reserved.

\section{Introduction}

High-performance cementitious materials can be very prone to early age cracking due to high autogenous shrinkage values. Autogenous shrinkage is defined as the external-macroscopical (bulk) dimensional reduction (volume or linear) of the cementitious system, which occurs under sealed isothermal unrestrained conditions [1]. The increased autogenous shrinkage is mainly related to the low water/binder ratio. However, also the addition of fine powders like silica fume and fly ash can have an important role [2,3].

Autogenous shrinkage is the result of the chemical shrinkage occurring during the cement hydration process. In fluid state of the cementitious material, the chemical shrinkage is totally converted into autogenous shrinkage. As soon as the cementitious material shows a percolating cluster of hydration products, the free chemical shrinkage is obstructed, and the autogenous shrinkage deviates from the chemical shrinkage $[1,2]$. In this stage, the autogenous shrinkage is influenced by several mechanisms: changes in the surface tension of the solid gel particles, disjoining pressure, and capillary tension [1].
The onset of cluster formation of the hydration products marks the start of internal stress formation due to the autogenous shrinkage. The determination of this particular percolation threshold is not straightforward, and many approaches have been followed: based on the Vicat needle test, based on strength development, based on development of heat of hydration, based on ultrasonic testing of the fresh concrete, ... [4-7].

Self-compacting concrete (SCC) is a very fluid concrete showing several advantages such as environmental, human, technological and economical [8]. However, because of the particular composition, often resulting in a higher fines content and a higher paste volume, SCC could be more sensitive to cracking than traditionally vibrated concrete (TVC) [9]. Besides the effect of increased paste volume, the autogenous shrinkage is also influenced by changes in the capillary network due to the presence of mineral additions. The change in pore structure of capillaries induces a change in magnitude of self-desiccation shrinkage [10].

In this paper, the effect of mineral filler type on the autogenous shrinkage of powder-type self-compacting concrete is experimentally investigated.

\section{Materials and concrete compositions}

Within the experimental programme, the behaviour of 7 selfcompacting concretes (SCC) has been studied, as listed in Table 1. The

\footnotetext{
* Corresponding author.

E-mail address: Geert.DeSchutter@ugent.be (G. De Schutter).
} 
Table 1

Mix composition.

\begin{tabular}{|c|c|c|c|c|c|c|c|c|}
\hline & & SCC20 & SCC21 & SCC22 & SCC23 & SCC24 & SCC26 & SCC27 \\
\hline River gravel 4/14 & {$\left[\mathrm{kg} / \mathrm{m}^{3}\right]$} & 698 & 698 & 698 & 698 & 698 & 698 & 698 \\
\hline River sand $0 / 5$ & {$\left[\mathrm{~kg} / \mathrm{m}^{3}\right]$} & 853 & 853 & 853 & 853 & 853 & 853 & 853 \\
\hline CEM I 52.5 R HES & {$\left[\mathrm{kg} / \mathrm{m}^{3}\right]$} & 360 & 360 & 360 & 360 & 360 & 300 & 360 \\
\hline \multirow[t]{2}{*}{ Limestone filler 1} & {$\left[\mathrm{~kg} / \mathrm{m}^{3}\right]$} & 240 & - & - & - & 240 & 300 & 240 \\
\hline & [vol.\%] & 8.89 & - & - & - & 8.89 & 11.11 & 8.89 \\
\hline \multirow[t]{2}{*}{ Limestone filler 2} & {$\left[\mathrm{~kg} / \mathrm{m}^{3}\right]$} & - & 240 & - & - & - & - & - \\
\hline & [vol.\%] & - & 8.86 & - & - & - & - & - \\
\hline \multirow[t]{2}{*}{ Quartzite filler } & {$\left[\mathrm{kg} / \mathrm{m}^{3}\right]$} & - & - & 240 & - & - & - & - \\
\hline & [vol.\%] & - & - & 9.09 & - & - & - & - \\
\hline \multirow[t]{2}{*}{ Fly ash } & {$\left[\mathrm{kg} / \mathrm{m}^{3}\right]$} & - & - & - & 240 & - & - & - \\
\hline & [vol.\%] & - & - & - & 10.21 & - & - & - \\
\hline Water & {$\left[1 / \mathrm{m}^{3}\right]$} & 165 & 165 & 165 & 165 & 165 & 165 & 198 \\
\hline \multirow[t]{2}{*}{ Superplasticizer A } & {$[\mathrm{m} \% \mathrm{C}]$} & 1.25 & 1.39 & 1.39 & 1.88 & - & 1.25 & 0.69 \\
\hline & {$\left[\mathrm{kg} / \mathrm{m}^{3}\right]$} & 4.50 & 5.00 & 5.00 & 6.75 & - & 3.75 & 2.50 \\
\hline \multirow[t]{2}{*}{ Superplasticizer B } & {$[\mathrm{m} \% \mathrm{C}]$} & - & - & - & - & 1.39 & - & - \\
\hline & {$\left[\mathrm{kg} / \mathrm{m}^{3}\right]$} & - & - & - & - & 5.00 & - & - \\
\hline $\mathrm{W} / \mathrm{C}$ & {$[-]$} & 0.46 & 0.46 & 0.46 & 0.46 & 0.46 & 0.55 & 0.55 \\
\hline $\mathrm{C} / \mathrm{P}$ & {$[-]$} & 0.6 & 0.6 & 0.6 & 0.6 & 0.6 & 0.5 & 0.6 \\
\hline $\mathrm{W} / \mathrm{P}$ & {$[-]$} & 0.28 & 0.28 & 0.28 & 0.28 & 0.28 & 0.28 & 0.33 \\
\hline
\end{tabular}

self-compactability of the SCC mixes is obtained by using a combination of Portland cement CEM I 52.5 R HES, filler and a polycarboxyl ether (PCE) superplasticiser (SP). In all SCC mixes, a constant powder quantity $\left(600 \mathrm{~kg} / \mathrm{m}^{3}\right)$ is applied, in which the powder content $(\mathrm{P})$ is defined as the sum of the cement and filler content.

In concretes SCC20 to SCC23, the filler type is changed, while the filler content, the water/cement ratio $(\mathrm{W} / \mathrm{C}$ ) and the cement/powder ratio $(C / P)$ remain unchanged. Two types of limestone filler, 1 and 2 , one type of quartzite filler, and one fly ash have been used in the experiments. The limestone fillers have different grading curves, filler 1 being coarser. Fig. 1 shows the grading curves of the different fillers, while some material properties are listed in Table 2. The Portland cement CEM I 52.5 R HES has a median particle size of $7.5 \mu \mathrm{m}$.

The superplasticiser A is replaced by superplasticiser B in mix SCC24. Both superplasticisers are third generation polycarboxyl ethers, however from different suppliers, and having a different solid concentration. A slightly higher quantity of superplasticiser B is needed to compensate for its slightly lower solid concentration and lower plasticising effect in comparison with superplasticiser $A$.

In mix SCC26, part of the cement is replaced by limestone filler 1 , maintaining the water/powder ratio (W/P), while lowering the cement/ powder ratio $(\mathrm{C} / \mathrm{P})$ and increasing the water/cement ratio $(\mathrm{W} / \mathrm{C})$. In mix SCC27, a lower amount of superplasticiser is used, while a higher amount of water is added to obtain a comparable workability. This results in a

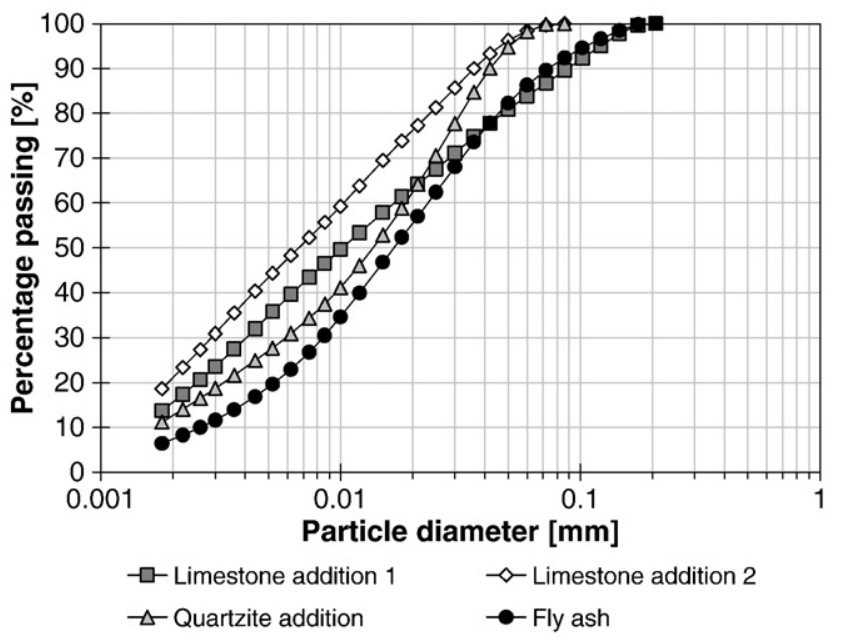

Fig. 1. Filler grading curves. higher water/cement ratio $(\mathrm{W} / \mathrm{C})$ and a higher water/powder ratio $(\mathrm{W} / \mathrm{P})$, however with unchanged cement/powder ratio (C/P).

The mixes are prepared in a planetary pan mixer. The dry materials are introduced first. During the first $15 \mathrm{~s}$ of mixing, water at a temperature of $20^{\circ} \mathrm{C}$ is added. 1 min later, the mixing is stopped for $15 \mathrm{~s}$, during which the SP is added to the concrete. Mixing continues for another 2 min.

On the listed mixes, several other properties have been investigated in the framework of an inter-university project in Belgium. More details and results can be found in literature [11-13].

\section{Test methods}

\subsection{Autogenous deformation}

In literature [14], different test methods for autogenous shrinkage can be found. Two main categories can be noticed: linear measurements and volumetric measurements. It is shown that the autogenous shrinkage measured with volumetric methods is significantly higher than results from linear measurements [15]. The different hypotheses formulated to explain this difference are beyond the scope of this paper.

At the Magnel Laboratory for Concrete Research, Ghent University, a vertical dilatometer for concrete has been developed [16]. Within the newly developed dilatometer, the fresh concrete is cast into a vertical Teflon tube, with a Teflon foil in between (Fig. 2). After mixing the concrete and filling the Teflon tubes, the concrete samples are placed into the measuring frame, inside a climate room. Linear vertical shrinkage measurements can start immediately after casting, by means of LVDT-transducers. Temperature measurements are performed in parallel, in order to take into account the effect of the heat of hydration on the autogenous shrinkage results.

Table 2

Specific mass and Blaine fineness of aggregates, cement and fillers.

\begin{tabular}{lll}
\hline & $\begin{array}{l}\text { Specific mass } \\
{\left[\mathrm{kg} / \mathrm{m}^{3}\right]}\end{array}$ & $\begin{array}{l}\text { Blaine fineness } \\
{\left[\mathrm{m}^{2} / \mathrm{kg}\right]}\end{array}$ \\
\hline River gravel 4/14 & 2640 & - \\
River sand 0/5 & 2640 & - \\
CEM I 52.5 R HES & 3130 & 600 \\
Limestone filler 1 & 2700 & 338 \\
Limestone filler 2 & 2710 & 558 \\
Quartzite filler & 2640 & 388 \\
Fly ash & 2350 & 346 \\
\hline
\end{tabular}




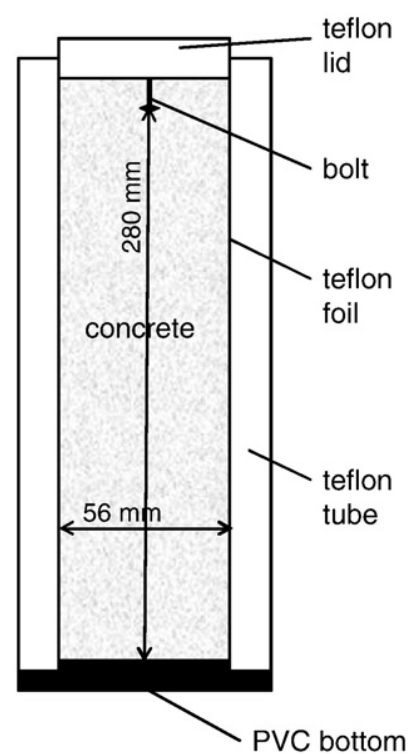

Fig. 2. Schematic view of vertical linear dilatometer for concrete.

\subsection{Ultrasonic testing of fresh concrete}

The ultrasonic transmission method is known to be very sensitive for microstructural changes in materials $[17,18]$. Immediately after mixing and casting, ultrasonic monitoring is performed. The device consists of a PC-connected controller allowing up to 8 simultaneous measuring channels, two of which are used in this research. Each measuring channel is composed of a cylindrical flexible silicone mould and an ultrasonic sender and receiver pair. The mould can hold cylindrical concrete or mortar samples measuring up to $70 \mathrm{~mm}$ across and $60 \mathrm{~mm}$ high. It allows the lateral fitting and fixing of the senderreceiver pair, in direct contact with the fresh concrete or mortar sample, for the measurement of the ultrasonic wave transit time in through-transmission. The sample can be sealed from the air with a silicone-fixed cover.

The p-wave narrow-band ultrasonic tester pair has a resonant frequency of $25 \mathrm{kHz}$. The transmission time is measured with a precision of $0.1 \mu \mathrm{s}$, using a threshold onset picking algorithm. Each reported measurement of the through-transmission time is the mean of 6 consecutive measurements, within $1 \mathrm{~s}$. This means transmission time is then used to calculate the p-wave velocity of the sample at the given moment, using a predefined distance between the sender and the receiver. The hydration of the concrete is monitored for $48 \mathrm{~h}$ after the start of the test. The obtained results can be used to define the moment of percolation of the solid structure (time zero).

\subsection{Mercury intrusion porosimetry (MIP)}

Mercury intrusion porosimetry has been well described in literature with its pros and cons, e.g. in [19-21]. Unlike wetting liquid, mercury cannot enter the pores spontaneously. The pores can only be filled at certain corresponding pressure level. The pressure on the mercury is gradually increased and the pores that are connected to the surface, i.e. to the mercury, are gradually filled depending on the pressure level. This procedure is known as intrusion. The extrusion procedure is opposite to the intrusion procedure: after reaching the highest pressure, the pressure is gradually decreased and mercury is then desorbed from the porous sample. Due to the ink-bottle effect, the MIP method is not fully appropriate for evaluating the pore size distribution of cementitious materials. Furthermore, the basic assumptions in the cylindrical pore model (see further) are not fully in agreement with the characteristics of a real pore structure. Nevertheless, MIP it is still a very effective aid to obtain an overview

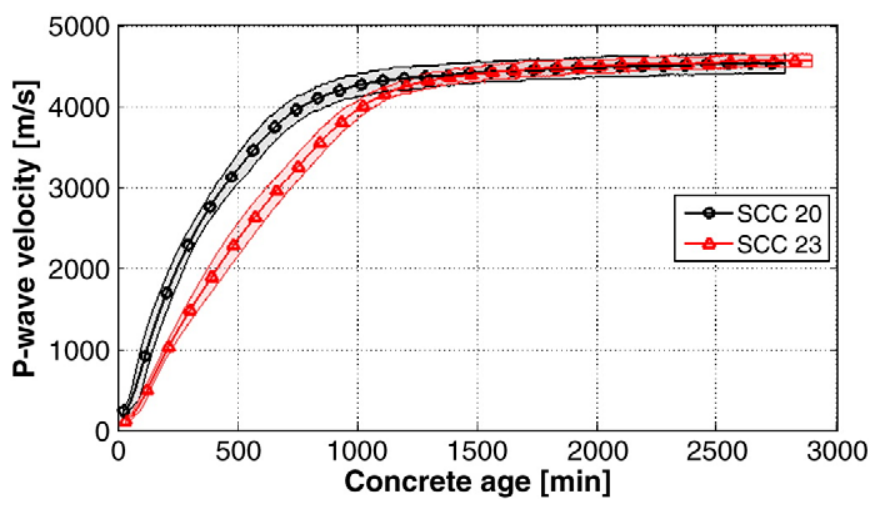

Fig. 3. p-wave velocity (in $\mathrm{m} / \mathrm{s}$ ) as a function of time, for the mixes SCC20 and SCC23.

of the pore system and its connectivity, especially when the ink-bottle effect is carefully taken into account [21].

The cylindrical pore model is applied for the interpretation of the test results. With this model, the well-known Washburn equation [19] is valid to estimate the diameter of the cylindrical pores intruded at each pressuring step:

$d=-4 r \cdot \cos \vartheta / P$

where $d$ is the diameter of the cylindrical pore being intruded; $r$ is the surface tension of the mercury; $\vartheta$ is the contact angle of the mercury on the solid; $P$ is the applied pressure. In this study, a surface tension value of $0.485 \mathrm{~N} / \mathrm{m}$ and a contact angle of $130^{\circ}$ were used for the calculation of the pore diameters.

\section{Results}

\subsection{Continuous ultrasonic monitoring}

As a typical example, Fig. 3 shows the p-wave velocity (in $\mathrm{m} / \mathrm{s}$ ) and Fig. 4 shows the p-wave velocity gradient as a function of time, for the mixes SCC20 and SCC23. The velocity curve is a polynomial fit to the mean of all test results for the considered mix. The standard deviation is indicated by the shaded zone around the velocity curve. The time (in minutes) on the axis starts with the addition of the water to the concrete. The time corresponding to the maximum gradient of the $\mathrm{p}$ wave velocity, coinciding with the inflection point of the velocity curves, is giving an estimation of time zero, i.e. the start of setting, or the onset of percolating cluster formation. For SCC20, time zero is found to be $103 \mathrm{~min}$, while for SCC23 it is $143 \mathrm{~min}$. An overview of the experimentally obtained time-zero values for all mixes is given in Table 3.

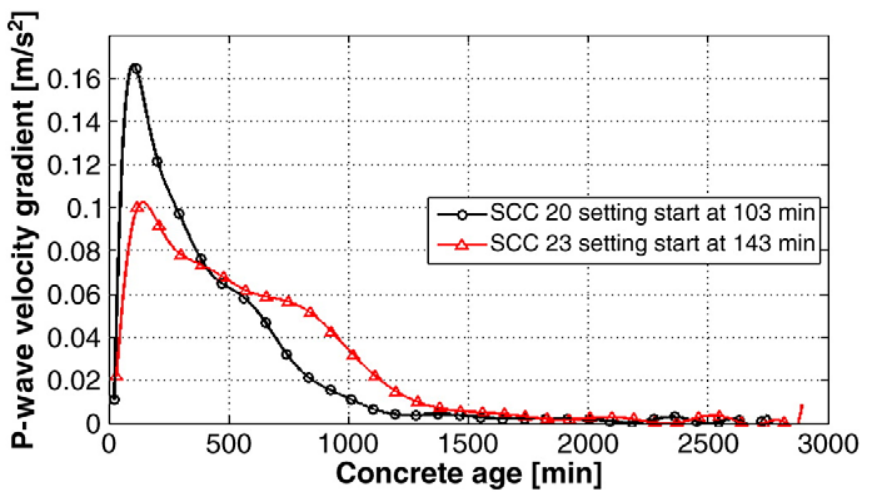

Fig. 4. p-wave velocity gradient as a function of time, for the mixes SCC20 and SCC23. 
Table 3

Time-zero values for all tested mixes.

\begin{tabular}{llllllll}
\hline Mix & SCC20 & SCC21 & SCC22 & SCC23 & SCC24 & SCC26 & SCC27 \\
\hline Time zero (min) & 103 & 96 & 261 & 143 & 96 & 103 & 79 \\
Time zero $(\mathrm{h})$ & 1.72 & 1.60 & 4.35 & 2.38 & 1.60 & 1.72 & 1.32 \\
$\varepsilon_{\mathrm{P}}(\mu \mathrm{m} / \mathrm{m})$ & 53 & 416 & 504 & 485 & 241 & 52 & 576 \\
$t_{\mathrm{P}}(\mathrm{h})$ & 11.30 & 12.98 & 12.04 & 17.80 & 10.57 & 10.75 & 11.72 \\
$\varepsilon_{\mathrm{f}}(\mu \mathrm{m} / \mathrm{m})$ & -138 & -137 & -116 & -174 & -193 & -84 & -69 \\
$\varepsilon_{\mathrm{P}}-\varepsilon_{\mathrm{f}}(\mu \mathrm{m} / \mathrm{m})$ & 211 & 575 & 624 & 667 & 436 & 145 & 655 \\
\hline
\end{tabular}

\subsection{Autogenous deformation}

Fig. 5 shows the experimentally obtained evolutions of the autogenous deformation for all mixes. All curves are shown starting from the respective time-zero values as obtained by means of ultrasonic monitoring, and as listed in Table 3. Fig. 6 shows a detail of Fig. 5 , for the time period up to $24 \mathrm{~h}$. Each curve is the average result of two individual measurements, obtained on two different specimens from the same mix. The variability between mixes has not been studied in this experimental programme. However, earlier research [15] with this testing equipment showed that deviations between identical mixes are below $10 \%$.

From the experimentally obtained autogenous deformation curves, some key values have been determined, like the maximum peak value $\varepsilon_{\mathrm{P}}$, the time $t_{\mathrm{P}}$ for which this maximum occurs, the final

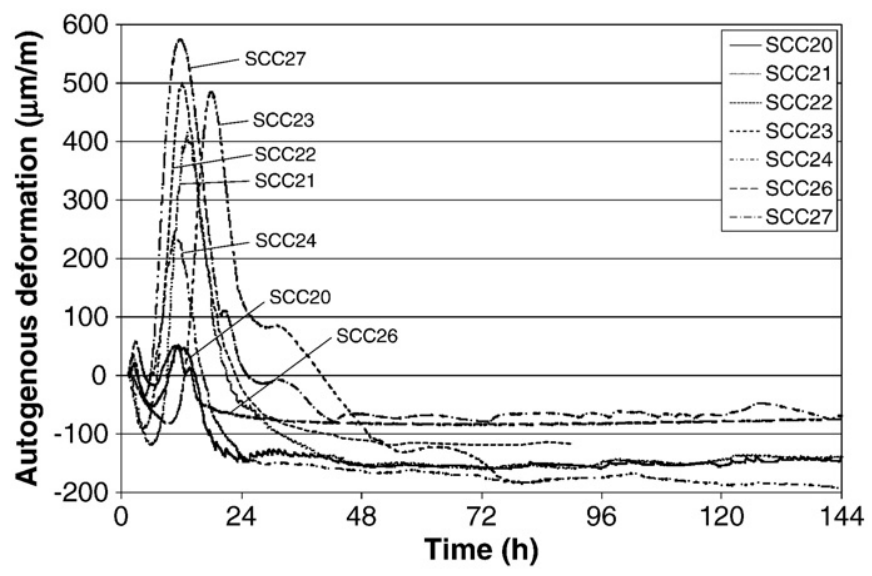

Fig. 5. Autogenous deformation (positive values $=$ swelling, negative values $=$ shrinkage).

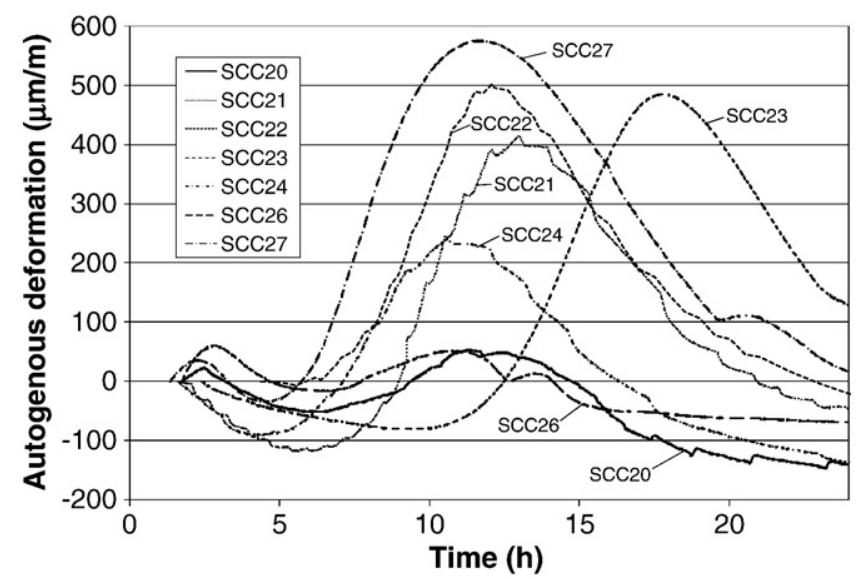

Fig. 6. Autogenous deformation (positive values = swelling, negative values = shrinkage) up to $24 \mathrm{~h}$

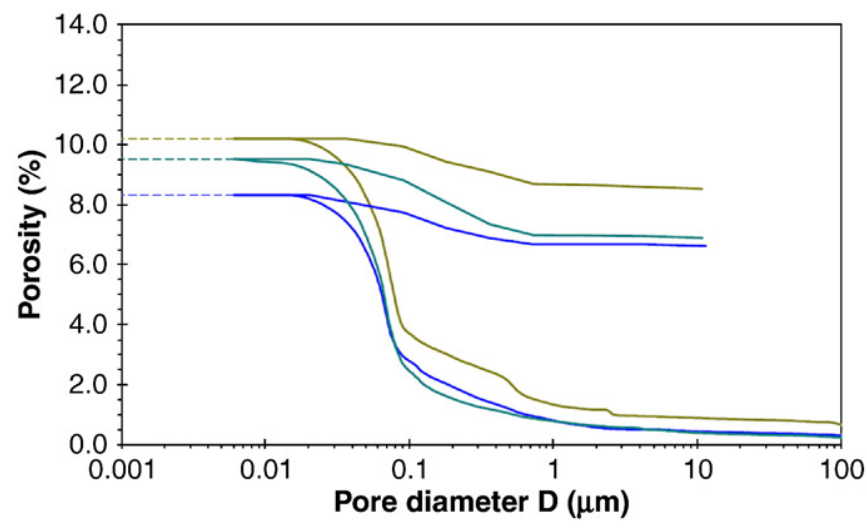

Fig. 7. Total MIP intrusion and extrusion porosity as obtained on three different samples of mix SCC20.

value $\varepsilon_{\mathrm{f}}$ at the end of the test, and the difference between maximum and minimum value $\varepsilon_{\mathrm{P}}-\varepsilon_{\mathrm{f}}$. These values are summarised in Table 3 .

\subsection{Mercury intrusion porosimetry (MIP)}

MIP measurements have been performed on hardened concrete samples, with an age of 120 days or older. Capillary pores between $0.005 \mu \mathrm{m}$ and $10 \mu \mathrm{m}$ have been measured. As an example, Fig. 7 shows the total intrusion and extrusion porosity as obtained on three different samples for mix SCC20. The average effective porosity, based on the extrusion curves, is $1.9 \%$. Fig. 8 shows the derivative curve for the three samples of SCC20. The average critical pore diameter for SCC20 is $64 \mathrm{~nm}$. No significant differences have been found between the critical pore diameters of the different mixes.

\section{Analysis and discussion}

The time-zero values for the limestone filler based mixes SCC20, SCC21, SCC24 and SCC26 area are all within the range of $1.60 \mathrm{~h}$ to $1.72 \mathrm{~h}$. For mix SCC22, based on quartzite filler, time zero is equal to $4.35 \mathrm{~h}$, which is significantly higher. Also for mix SCC23, based on fly ash, time zero is significantly higher $(2.38 \mathrm{~h})$. The observed differences depending on the nature of the filler are most probably due to the significant accelerating effect of limestone filler on the cement hydration [22-27], while quartzite filler does not influence the induction period $[22,26]$. Fly ash is also known to often have a slight accelerating effect on cement hydration [28], although not as significant as limestone filler. For mix SCC27, a slightly lower timezero value is noticed $(1.32 \mathrm{~h})$, probably explained by the reduced content of superplasticiser. As polycarboxylate-based superplasticisers can have a slight retarding effect [29], a reduction in

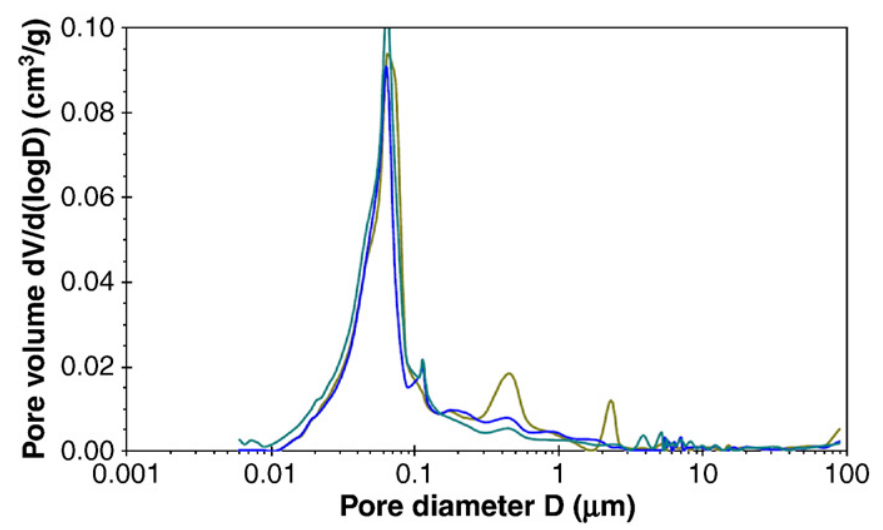

Fig. 8. MIP derivative curve for the three samples of SCC20. 
superplasticiser content leads to a slight acceleration of setting, explaining the observed reduction in time zero for mix SCC27.

When evaluating the autogenous deformation curves given in Figs. 5 and 6, it is remarkable to see that a very high swelling peak is occurring for most of the tested mixes. Autogenous swelling during the first day has also been reported by other researchers for medium or high $\mathrm{W} / \mathrm{C}$ ratio [30]. It is clear that the obtained swelling peaks are not measurement artefacts caused by a temperature increase of the specimens due to the heat of hydration, as a correction has been made based on the measured temperature development, considering a coefficient of thermal expansion equal to $10.10^{-6} /{ }^{\circ} \mathrm{C}$. Moreover, the temperature increase of the specimens $\left(<2{ }^{\circ} \mathrm{C}\right.$ in the centre of the specimens) is too low to possibly explain the observed swelling peak in case no temperature corrections would have been made. The swelling behaviour is also not caused by reabsorption of bleeding water, as no significant bleeding has been observed during the tests.

According to Termkhajornit et al. [3] expansion might be caused by ettringite formation. Baroghel-Bouny et al. [30] also mention that the swelling after setting may be attributed to structural swelling caused by the formation of AFt needles (tri-sulphate phases) and AFm crystals (mono-sulphate phases), although from a chemical point of view the formation of these products leads to a decrease in solid volumes and contributes to chemical shrinkage. However, according to Baroghel-Bouny et al. [30], the growth of $\mathrm{Ca}(\mathrm{OH})_{2}$ crystals can be more important with regard to the occurrence of swelling, especially when the cement has a low aluminate content. The crystal growth generates a crystallisation pressure on the pore walls, which can induce expansion of the microstructure. This expansion process is more significant for higher $\mathrm{W} / \mathrm{C}$ ratio. When looking at the values of the expansion peaks shown in Fig. 6 (up to $500 \mu \mathrm{m} / \mathrm{m}$ ), and taking into account that the tests have been performed on concrete, it seems however that the mentioned crystallisation pressures alone cannot fully explain the observed swelling peaks.

Further explanation of swelling of limestone filler based mixes can be found in the work of Esping [31]. For concrete mixes with full cement replacement by limestone filler, a significant 'autogenous' swelling was observed, with peak values within the same range as shown in Fig. 6, in one case even up to $800 \mu \mathrm{m} / \mathrm{m}$. According to Esping [31], the expansion can be explained by water absorption by the filler, and by the disjoining pressure inducing expansion. This process is influenced by the fineness (specific surface) of the limestone filler, the finer one giving a higher expansion peak, as confirmed by the results obtained for mix SCC20 (coarser limestone filler 1) and mix SCC21 (finer limestone filler 2).

From the results shown in Fig. 6, it is clear that also mix SCC22 (containing quartzite filler) and mix23 (containing fly ash) clearly show a swelling peak, which most probably can be explained by the same process of water absorption and disjoining pressure. However, although the quartzite filler and the fly ash are somewhat coarser than limestone filler 2, a larger swelling peak occurred. This might indicate that not only the fineness of the filler is important, but also the chemical nature of the filler surface.

The fact that the swelling peak in case of mix SCC27 is higher can be explained by the higher water content in comparison with the other mixes. Changing the superplasticizer, as in the case of mix SCC24, also seems to have a potential influence on the swelling behaviour during the first day. This can be understood by the interaction between the superplasticizer and the filler surface, intervening with the water absorption phenomenon.

It can be summarised that the observed swelling peak is not a measuring artefact, but is caused mainly by water absorption on the filler surface and resulting disjoining pressure. Some part of the swelling peak might also be caused by the $\mathrm{Ca}(\mathrm{OH})_{2}$ crystallisation. The fineness of the filler is an important factor for this swelling behaviour, although also the nature of the filler seems to have an influence. The superplasticiser also interacts with the fillers, influencing the swelling behaviour.
After swelling, as soon as lack of water occurs, meniscus-generated capillary tension will occur, causing contraction. The final autogenous shrinkage values of mixes SCC20 and SCC21, made with the two different limestone fillers, does not differ. The values of mixes SCC22 (quartzite filler) and SCC23 (fly ash) are slightly different, although not very significant. This can be understood by the MIP measurements, showing that the critical pore diameter for the different mixes differs not significantly. As the pore structure, e.g. in terms of average pore radius, is influencing the autogenous shrinkage values, no significant differences have to be expected for the mixes with the different filler types mentioned here.

A significantly lower final autogenous shrinkage value is found however for mixes SCC26 and SCC27. This can be easily understood by the higher $\mathrm{W} / \mathrm{C}$ ratio in these mixes.

Changing the superplasticiser (mix SCC24) leads to a different (in this case: higher) final autogenous shrinkage value. The mechanism in this respect is not clear, but it illustrates that different superplasticisers, even of the same type (in this case: PCE), can have a different effect on the autogenous shrinkage. As for mix SCC24, the same critical pore diameter has been obtained as for mix SCC20, it is not clear whether the plasticiser influence has anything to do with a change in microstructure.

\section{Conclusions}

Based on an experimental programme, including autogenous shrinkage tests on concrete, ultrasonic monitoring of fresh concrete, and mercury intrusion porosimetry, the influence of the filler type on the autogenous shrinkage of self-compacting concrete has been investigated. The following conclusions have been obtained.

- The onset of percolating structure formation (time zero) is influenced by the filler type due to a possible accelerating effect of the filler on the cement hydration. Limestone filler accelerates the hydration process, and reduces time zero, while this is not the case when using quartzite filler. Using fly ash, showing only a slight acceleration, a slight reduction of time zero is obtained.

- A very significant swelling peak is noticed during the first day. This swelling peak is not a measuring artefact, but is caused mainly by water absorption on the filler surface and resulting disjoining pressure. Some part of the swelling peak might also be caused by $\mathrm{Ca}(\mathrm{OH})_{2}$ crystallisation. The fineness of the filler is an important factor for this swelling behaviour, although also the nature of the filler seems to have an influence. The superplasticiser also interacts with the fillers, influencing the swelling behaviour.

- The different filler types used in this study did not lead to significant differences in critical pore diameter of the microstructure. This might explain why no significant differences have been found in final autogenous shrinkage values using the different filler types.

\section{References}

[1] K. Kovler, O.M. Jensen (Eds.), 'Internal Curing of Concrete', State-of-the-art report of RILEM Technical Committee 196-ICC, RILEM Report 41, RILEM Publications S.A.R.L, ISBN: 978-2-35158-009-7, 2007, p. 140.

[2] O.M. Jensen, P.F. Hansen, Autogenous deformation and change of the relative humidity in silica fume-modified cement paste, ACI Materials Journal 93 (6) (1996) 539-543.

[3] P. Termkhajornkit, T. Nawa, M. Nakai, T. Saito, Effect of fly ash on autogenous shrinkage, Cement and Concrete Research 35 (2005) 473-482.

[4] A. Bentur (Ed.), 'Early Age Cracking in Cementitious Systems', RILEM, Report 25, ISBN: 2-912143-33-0, 2003, p. 388.

[5] De Schutter G., 'Fundamental and Practical Study of Thermal Stresses in Hardening Massive Concrete Element' (in Dutch), Doctoral Thesis, Magnel Laboratory for Concrete Research, Ghent University, Belgium, 1996, pp. 364.

[6] G. De Schutter, L. Taerwe, Degree of hydration based description of mechanical properties of early age concrete, Materials and Structures 29 (July 1996) 335-344.

[7] C. Miao, Q. Tian, W. Sun, J.P. Liu, Water consumption of the early-age paste and the determination of "time-zero" of self-desiccation shrinkage, Cement and Concrete Research 37 (11) (2007) 1496-1501. 
[8] De Schutter G., Bartos P., Domone P., Gibbs J., 'Self-Compacting Concrete', Whittles Publishing, Caithness, UK, CRC Press, Taylor \& Francis Group, Boca Raton, USA ISBN 978-1904445-30-2, USA ISBN 978-1-4200-6833-7, 2008, pp. 296.

[9] E. Rozière, S. Granger, Ph. Turcry, A. Loukili, Influence of paste volume on shrinkage cracking and fracture properties of self-compacting concrete, Cement \& Concrete Composites (April 2007) 626-636.

[10] M.S. Meddah, A. Tagnit-Hamou, Pore structure of concrete with mineral admixtures and its effect on self-desiccation shrinkage, ACI Materials Journal 106 (3) (2009) 241-250.

[11] G. Heirman, L. Vandewalle, D. Van Gemert, J. Elsen, V. Boel, K. Audenaert, G. De Schutter, B. Desmet, J. Vantomme, Influence of Mineral Additions and Chemica Admixtures in SCC on Microcracking and Durability: Overview of a Belgian Research Project, in: G. De Schutter, V. Boel (Eds.), 5th International RILEM Symposium on Self-Compacting Concrete, RILEM Proceedings PRO 54, RILEM Publications S.A.R.L, vol. 2, ISBN: 978-2-35158-047-9, 2007, pp. 773-778.

[12] G. Heirman, L. Vandewalle, D. Van Gemert, V. Boel, K. Audenaert, G. De Schutter, B. Desmet, J. Vantomme, Time-dependent deformations of limestone powder type self-compacting concrete, Engineering Structures 30 (10) (2008) 2945-2956.

[13] G. Heirman, R. Hendrickx, L. Vandewalle, D. Van Gemert, D. Feys, G. De Schutter, B. Desmet, J. Vantomme, Integration approach of the Couette inverse problem of powder type self-compacting concrete in a wide-gap cylinder rheometer: Part Il. Influence of mineral additions and chemical admixtures on the shear thickening flow behaviour, Cement and Concrete research 39 (2009) 171-181.

[14] T.A. Hammer, O. Bjontegaard, E. Sellevold, Measurement Methods for Testing of Early Age Autogenous Strains, Proceedings of the International RILEM Conference, RILEM PRO 23, 2002, pp. 217-228.

[15] L. Barcelo, S. Boivin, S. Rigaud, P. Acker, B. Clauvaud, Linear vs. Volumetric Autogenous Shrinkage Measurements: Material Behaviour or Experimenta Artefact? in: B. Persson, G. Fagerlund (Eds.), Proceedings of the Second International Research Seminar on Self-desiccation and Its Importance in Concrete Technology, 1999, Lund, Sweden.

[16] B. Craeye, G. De Schutter, Experimental Evaluation of Mitigation of Autogenous Shrinkage by Means of a Vertical Dilatometer for Concrete, in: O.M. Jensen, P. Lura K. Kovler (Eds.), Proceedings of the International RILEM Conference on Volume Changes of Hardening Concrete: Testing and Mitigation, ISBN: 2-35158-004-4, August 2006, pp. 21-30, Lyngby, Denmark.

[17] C.U. Grosse, H.W. Reinhardt, M. Krüger, R. Beutel, Ultrasound Throughtransmission Techniques for Quality Control of Concrete during Setting and Hardening, Proceedings of Advanced Testing of Fresh Cementitious Materials, August 2006, pp. 83-93, Stuttgart, Germany.
[18] K. Van Den Abeele, W. De Sadeleer, G. De Schutter, M. Wevers, Active and passive monitoring of the early drying process in concrete using linear and nonlinear acoustics, Cement and Concrete Research 39 (2009) 426-432.

[19] E.W. Washburn, Proceedings of the National Academy of Sciences 7 (1921) 115.

[20] Cook R.A., Fundamentals of Mercury Intrusion Porosimetry and Its Application to Concrete Materials Science, Master of Science Thesis, Cornell University, 1991.

[21] S. Diamond, Mercury porosimetry - an inappropriate method for the measurement of pore size distributions in cement-based materials, Cement and Concrete Research 30 (2000) 1517-1525.

[22] Poppe A.-M., 'Influence of Fillers on Hydration and Properties of Self-compacting Concrete' (in Dutch), Doctoral Thesis, Magnel Laboratory for Concrete Research, Ghent University, Belgium, 2004, pp.240.

[23] A.-M. Poppe, G. De Schutter, Cement hydration in the presence of high filler contents, Cement \& Concrete Research 35 (2005) 2290-2299.

[24] G. Ye, X. Liu, G. De Schutter, A.-M. Poppe, L. Taerwe, Influence of limestone powder used as filler in SCC on hydration and microstructure of cement pastes, Cement \& Concrete Composites 29 (2007) 94-102.

[25] G. Ye, X. Liu, A.-M. Poppe, G. De Schutter, K. Van Breugel, Numerical simulation of the hydration process and the development of microstructure of self-compacting cement paste containing limestone as filler, Materials and Structures 40 (2007) 865-875.

[26] E.-H. Kadri, S. Aggoun, G. De Schutter, K. Ezziane, Combined effect of chemical nature and fineness of mineral powders on Portland cement hydration, Materials and Structures (2009), doi:10.1617/s11527-009-9519-6.

[27] M. Bouasker, P. Mounanga, P. Turcry, A. Loukili, A. Khelidj, Chemical shrinkage of cement pastes and mortars at very early age: effect of limestone filler and granular inclusions, Cement and Concrete Composites 30 (2008) 13-22.

[28] G. Baert, S. Hoste, G. De Schutter, N. De Belie, Reactivity of fly ash in cement paste studied by means of thermal analysis and isothermal calorimetry, Journal of Thermal Analysis and Calorimetry 94 (2) (2008) 485-492.

[29] F. Winnefeld, A. Zingg, L. Holzer, R. Figi, J. Pakusch, S. Becker, Interaction of Polycarboxylate-based Superplasticizer and Cements: Influence of Polymer Structure and C3A-content of Cement, in: J.J. Beaudoin, J.M. Makar, L. Raki (Eds.), Proc 12th International Congress on the Chemistry of Cement, Montréal, CD-ROM, 2007.

[30] V. Baroghel-Bouny, P. Mounanga, A. Khelidj, A. Loukili, N. Rafaï, Autogenous deformations of cement pastes. Part II. W/C effects, micro-macro correlations, and threshold values, Cement and Concrete Research 36 (2006) 123-136.

[31] O. Esping, Effect of limestone filler $\mathrm{BET}\left(\mathrm{H}_{2} \mathrm{O}\right)$-area on the fresh and hardened properties of self-compacting concrete, Cement and Concrete Research 38 (2008) 938-944. 